\title{
NESTER - WADAH REKREASI DAN KEBUGARAN
}

\author{
Jesslyn ${ }^{1)}$, Budi Adelar Sukada ${ }^{2}$ \\ 1) Program Studi S1 Arsitektur, Fakultas Teknik, Universitas Tarumanagara, jesslyn.sulaiman97@yahoo.com \\ 2) Program Studi S1 Arsitektur, Fakultas Teknik, Universitas Tarumanagara, budisukada@yahoo.com \\ Masuk: 09-01-2020, revisi: 28-01-2020, diterima untuk diterbitkan: 09-05-2020 (doi: 10.24912/stupa.v2i1.6756)
}

\begin{abstract}
Abstrak
Menurut Ray Oldenburg tempat ketiga (Third Place), mengacu pada tempat di mana orang menghabiskan waktu antara rumah ('tempat pertama') dan tempat bekerja (tempat 'kedua'). Salah satu contoh tempat ketiga adalah pusat rekreasi. Menurut Daniel D. Mclean, rekreasi dapat mencakup berbagai kegiatan yang sangat luas, termasuk olahraga. Rekreasi olahraga merupakan jenis olahraga yang sengaja dilakukan untuk kepentingan pribadi, untuk bersenang-senang. Kehidupan di kota besar, seperti Jakarta yang penuh dengan aktivitas dan rutinitas dapat menimbulkan kejenuhan dan tekanan mental pada masyarakatnya. Berdasarkan data dari International Labour Organization, total jam kerja dalam seminggu di Jakarta meningkat pada tahun 2016 dengan total 32 jam dibandingkan dengan total jam kerja pada tahun 2006 yaitu 27 jam dan berdasarkan penelitian dari Organisation For Economic Co-Operation And Development $(O E C D)$, Indonesia berada di posisi 3 dengan negara yang paling buruk keseimbangan antara kerja dan kehidupan dengan angka mencapai $14,3 \%$. Menurut seorang psikolog, Kartasasmita, M. Psi, pekerjaan merupakan penyebab stress tertinggi pada seseorang. Dengan kondisi Jakarta yang seperti itu, diperlukan sarana yang dapat mewadahi kebutuhan rekreasi dan kebugaran masyarakat berupa Third Place. Tujuan proyek ini untuk meningkatkan kualitas hidup masyarakat perkotaan, dalam hal kesehatan dan kebugaran baik fisik maupun psikis tubuh. Metode desain yang digunakan yaitu komparasi yang mengacu kepada teori Place dalam Arsitektur menurut Christian Norberg Schulz. Program utama yang ditawarkan pada proyek ini terdapat area fitness, studio olahraga, spa, sauna, hydrotherapy pool, jogging track, bicycle track, yoga \& meditation park, dan area penunjang seperti sport retail dan tempat makan.
\end{abstract}

Kata kunci: arsitektur, kebugaran, relaksasi, rekreasi, tempat ketiga

\begin{abstract}
According to Ray Oldenburg Third Place, refers to the place where people spend time between home ('first place') and place of work ('second place'). One example of a third place is a recreation center. According to Daniel D. Mclean, recreation can include a very wide variety of activities, including sports. Sports recreation is a type of sport that is intentionally done for personal gain, for fun. Life in a big city, like Jakarta, which is full of activities and routines can cause boredom and mental stress on the community. Based on data from the International Labor Organization, total working hours in a week in Jakarta increased in 2016 with a total of 32 hours compared to total working hours in 2006 of 27 hours and based on research from the Organization for Economic Co-Operation and Development (OECD), Indonesia was in position 3 with the country with the worst balance between work and life with a figure reaching 14.3\%. According to a psychologist, Kartasasmita, M. Psi, work is the highest cause of stress on a person. With Jakarta's condition like that, needed a facility that can accommodate the recreational and fitness needs of the community in the form of Third Place. The aim of this project is to improve the quality of life of urban communities, in terms of physical and psychological health and fitness. The design method used is comparison which refers to the Place theory in Architecture according to Christian Norberg Schulz. The main programs offered in this project include a fitness area, sports studio, spa, sauna, hydrotherapy pool, jogging track, bicycle track, yoga \& meditation park, and supporting areas such as sports retail and dining areas.
\end{abstract}

Keywords: architecture, fitness, relaxation, recreation, third place 


\section{PENDAHULUAN}

Menurut Ray Oldenburg tempat ketiga (Third Place), mengacu pada tempat di mana orang menghabiskan waktu antara rumah ('tempat pertama') dan tempat bekerja (tempat 'kedua'). Contoh tempat ketiga adalah bar, kedai kopi, salon kecantikan, tempat pangkas rambut, arena bowling dan pusat rekreasi, tempat-tempat umum di mana orang bertemu, berkumpul, dan berkomunikasi (The Great Good Place, 1997). Dari pernyataan ini maka diketahui bahwa pusat rekreasi merupakan salah satu dari tempat ketiga. Menurut Daniel D. Mclean, rekreasi dapat mencakup berbagai kegiatan yang sangat luas, seperti olahraga, permainan, kerajinan, seni pertunjukan, seni rupa, musik, perjalanan, hobi, dan kegiatan sosial (Kraus' Recreation and Leisure in Modern Society Elevent Edition, 2018). Rekreasi olahraga merupakan jenis olahraga yang sengaja dilakukan untuk kepentingan pribadi, untuk bersenang-senang.

Jakarta merupakan salah satu kota terpadat di dunia dengan penduduk berjumlah 10.374.235 jiwa (2017). Kehidupan di kota besar, seperti Jakarta yang penuh dengan aktivitas dan rutinitas dapat menimbulkan kejenuhan dan tekanan mental pada masyarakatnya. Berdasarkan data dari International Labour Organization, total jam kerja dalam seminggu di Jakarta meningkat pada tahun 2016 dengan total 32 jam dibandingkan dengan total jam kerja pada tahun 2006 yaitu 27 jam (ILO, 2017) dan berdasarkan penelitian dari Organisation For Economic Co-Operation And Development (OECD), Indonesia berada di posisi 3 dengan negara yang paling buruk keseimbangan antara kerja dan kehidupan dengan angka mencapai 14,3\%, setelah Turki dan Korea Selatan, yang masing-masing mencapai 23,3\% dan 22,6\%. Menurut seorang psikolog, Kartasasmita, M. Psi, pekerjaan merupakan penyebab stress tertinggi pada seseorang. Sedangkan menurut penelitian di Yale University School of Medicine, stress karena pekerjaan pada manusia bisa mengakibatkan kematian mendadak karena ritme jantung yang tidak normal. Kesibukan atas tuntutan pekerjaan inilah secara tidak langsung sangat berdampak pada kondisi kesehatan, baik secara fisik (kebugaran tubuh) maupun jasmani (stress, gangguan atau kekacauan mental dan emosional).

Untuk mengatasi masalah tersebut dibutuhkan tempat yang dapat mewadahi masyarakat untuk beristirahat dari kesibukan yang dapat disebut sebagai Third Place. Masyarakat di perkotaan seperti Jakarta yang sibuk, mengabaikan kesehatan dirinya, termasuk aktivitas fisik dan kecukupan asupan nutrisi. Menurut Dokter spesialis gizi klinik dan Ketua Departemen IImu Gizi FKUI dr. Fiastuti Witjaksono, M.S, SpGK, Gym dilakukan tanpa arahan dari instruktur, serta melakukan diet tertentu tanpa pengawasan dokter dinilai sangat mengkhawatirkan karena mengabaikan keamanan untuk mendapatkan hasil instan.

Dengan kondisi Jakarta yang seperti itu, diperlukan sarana yang memenuhi kebutuhan rekreasi dan kebugaran masyarakat (Entertainment \& Hospitality). Sifat rekreasi ini juga sebagai sarana pelengkap kota sesuai dengan pendekatan tempat ketiga menurut Ray Oldenburg dan sifat melayani ini sebagai sarana untuk melayani kota sesuai dengan gerakan sehat.

Batasan masalah pada proyek ini, pertama program yang ditawarkan berupa aktivitas untuk rekreasi dan kebugaran yang dapat dilakukan pada waktu senggang, tidak terikat oleh jadwal tertentu. Serta kegiatan olahraga yang ada hanya untuk relaksasi, menyaluran hobi, dan tujuan kesehatan, bukan sebagai area latihan dengan standar pertandingan, perlombaan, ataupun olimpiade. Kedua, proyek tetap dapat digunakan oleh seluruh kalangan masyarakat, namun sasaran utama diperuntukan bagi masyarakat usia produktif bekerja.

Rumusan masalah utama pada proyek ini yaitu, "Bagaimana rancangan arsitektur yang tepat untuk meningkatkan kesehatan dan kebugaran sesuai dengan perilaku masyarakat saat ini?". Sehingga proyek ini memiliki tujuan utama untuk meningkatkan kualitas hidup masyarakat agar tetap menjaga kesehatan dan kebugaran tubuhnya sebagai salah satu cara pencegahan stress di tengah kesibukan tuntutan pekerjaan. Kondisi masyarakat yang sehat dan bugar dapat meningkatkan produktivitas kerjanya, sehingga berdampak pada pertumbuhan ekonomi kota. 


\section{KAJIAN LITERATUR}

\section{Tempat Ketiga}

Ditinjau dari sejarahnya tempat ketiga (Third Place) muncul pada tahun 1980 di Amerika. Berawal dari perkembangan revolusi industry yang memisahkan tempat tinggal dengan tempat kerja atau kawasan industri. Tempat tinggal mengidentifikasikan rumah disebut sebagai First Place sedangkan tempat kerja disebut sebagai Second Place. Pemisahan antara kawasan pemukiman dan kawasan kerja memunculkan kritik terhadap revolusi industri karena tidak menyediakan tempat atau kawasan rekreasi untuk para pekerja. Pembangunan pemukiman yang individual berpengaruh pada kehidupan sosial masyarakat. Masyarakat tidak saling mengenal, meskipun dalam satu lingkungan. Aktivitas masyarakat lebih banyak terjadi di dalam rumah dan tempat kerja yang menimbulkan rasa bosan, namun masyarakat tidak menemukan tempat di luar lingkungan rumah untuk berkegiatan dan berkumpul. Dampaknya adalah kebutuhan akan tempat ketiga (Third Place) guna menjembatani kehidupan dalam rumah dan aktifitas kerja dengan kegiatan informal. Third Place juga disebut sebagai a public meeting place (Larice dan Macdonad,2007).

\section{Karakteristik Third Place}

Menurut Oldenburg (1997), Third Place memiliki delapan karakteristik, yaitu :

- Neutural Ground: Occupants of third place have little to no obligation to be there, not tied down to the area financially, politically, legally or otherwise and are free to come \& go as they please.

- Leveler (a leveling place): Third place put no importance on individual's status in a society. Someone's economic or social status does not matter in a third place.

- Conversation in the Main Activity: Playful \& happy conversation is the main focus of activity in third places.

- Accessibility \& Accommodation: Third places must be open \& readily accessible to those who occupy them. They must also be accommodating, meaning they provide for the wants of their inhabitants \& all occupants feel their needs have been fulfilled.

- A Low Profile: Third Places are characteristically wholesome. The inside of a third place is without extravagance or grandiosity \& has a homely feel.

- The Regulars: Third Places harbor a number of regulars that help give the space it's tone, and help set the mood \& characteristic of the 0 . area. Regulars attract newcomers too.

- The Mood is Playful: The tone of conversation in third places is never marked with tension or hostility. Instead, third places have a playful nature, where witty conversation \& frivolous banter are highly valued.

- A Home Away from Home: Occupants of third places will often have the same feelings of warmth, possession, \& belonging as they would in their own homes.

\section{Sarana Olahraga sebagai Third Place}

Berdasarkan KBBI (2008), olahraga merupakan gerak badan untuk menguatkan dan menyehatkan tubuh. Olahraga dapat didefinisikan sebagai kebutuhan fisik dasar manusia untuk beristirahat, melakukan olah tubuh, dan juga menjaga kesehatan. Menurut Gold (1980), salah satu jenis kegiatan rekreasi adalah rekreasi fisik yang membutuhkan usaha fisik seperti pada aktivitas olahraga (lari, angkat beban, renang, dan lain sebaginya). Sebagai salah satu kebutuhan utama, kebutuhan untuk berolahraga ini seharusnya diakomodir dalam suatu perencanaan kota melalui penyediaan fasilitas sarana olahraga sebagai Third Place. Hal ini menjadi penting bagi penduduk kota karena lebih terikat pada kegiatankegiatan rutin sehari-harinya. Terkadang, kota ataupun wilayah sub-urban sering dianggap sebagai wilayah yang harus dihindarkan ketika waktu luang demi mencari suasana baru, namun daripada beranggapan demikian sebaiknya dipertimbangkan penciptaan sumbersumber rekreasi yang memiliki potensi bagus di wilayah kota/perkotaan (Gold, 1980). 


\section{Pengertian, dan Penyebab Stress}

Stress adalah suatu bentuk ketegangan fisik, psikis, emosi, dan mental, yang dialami oleh seseorang sehingga dapat mempengaruhi kegiatan orang tersebut. Penyebab stress terbagi menjadi dua yaitu secara internal (rasa pesimisme, ketidakmampuan menerima ketidakpastian, berpikir kaku, kurang fleksibel, berpikir negatif, perfeksionisme) dan secara eksternal (pekerjaan, hubungan, perekonomian, keluarga, kesibukan).

\section{Metode Penanganan Stress (Maxmore, 2019)}

- Melakukan hobi, dapat menenangkan pikiran, jiwa, dan memulihkan semangat.

- Komunikasi, menceritakan masalah atau beban hidup ke teman, keluarga, atau ahli, dapat mengurangi beban yang dialami.

- Meditasi, membersihkan pikiran sehingga dapat berkonsentrasi kembali.

- Mandi atau berendam, air memiliki efek yang baik dan ampuh untuk menyembuhkan serta menenangkan diri.

- Pijat, untuk relaksasi dan menormalkan kembali tekanan darah. Dengan pijat, hormon penyebab stress dapat berkurang hingga $53 \%$.

- Berteriak, dapat mengatasi stress dan membuat seseorang lebih relaks karena melepaskan perasaan yang mengganjal di hati dan pikirannya.

- Olahraga, membantu melepas hormon serotonin, membuat seseorang merasa senang.

- Rekreasi/ berlibur, untuk menghindari lingkungan negative ataupun sekedar menjauh dari rutinitas penyebab stress dan membuat perasaan lebih relaks.

- Aromaterapi, mempengaruhi emosi manusia sebab indera penciuman terhubung dengan pusat kendali emosional dalam otak manusia.

- Mendengarkan musik, melepaskan zat endorphin mengurangi stress \& rasa sakit.

- Tidur, dapat menghilangkan stress dan meningkatkan produktivitas.

- Berpikir positif, membuat seseorang bisa menerima beban yang diberikan karena memiliki sudut pandang yang baik terhadap beban tersebut.

- Makanan sehat, yang mengandung vitamin B, omega 3, asam folat, magnesium, dan vitamin $C$ dapat meredakan stress. Makanan yang mengandung antioksidan juga baik untuk dikonsumsi karena mampu memperlancar fungsi memori.

\section{Hal yang diperhatikan untuk Hidup Sehat}

a. Connect/ menghubungkan: Kuantitas dan kualitas koneksi sosial (berbicara dan mendengarkan keluarga atau orang lain) dapat meningkatkan kesejahteraan dan kesehatan fisik. Penyediaan ruang publik membuat orang saling terhubung serta menjadi sumber kesejahteraan bagi individu dan masyarakat luas. Kualitas alam, lansekap, dan hijau juga terbukti memiliki berbagai manfaat kesehatan.

b. Keep active/ Tetap aktif: Aktivitas fisik (berjalan, bersepeda, dan olahraga) dapat mengurangi gangguan mental maupun sakit fisik. Dengan penyediaan ruang latihan Bersama dan menciptakan pengalaman menarik di sepanjang rute sirkulasi (tampilan, seni, cahaya matahari, tanaman hijau).

\section{Wellness Center}

Menurut WHO Wellness merupakan proses aktif yang menjadikan sadar dan membuat pilihan menuju kehidupan yang sehat dan memuaskan. Sehingga dapat disimpulkan wellness merupakan sebuah kondisi kesadaran akan hidup sehat melalui pengembangan tubuh, pikiran, dan jiwa. Wellness Center merupakan wadah untuk masyarakat yang memiliki kesadaran tinggi akan kesehatan serta sebagai sarana untuk mengembangkan diri baik fisik dan non-fisik. 


\section{Jenis Olahraga}

Menurut Rusli lutan (2000), olahraga dapat dibedakan menjadi beberapa kelompok, antara lain sebagai berikut :

a. Olahraga Pendidikan: Jenis olahraga berdasarkan kurikulum pendidikan. Biasanya diajarkan oleh guru olahraga kepada para muris di sekolah untuk mencapai tujuan pendidikan.

b. Olahraga Rekreasi: Jenis olahraga yang sengaja dilakukan untuk kepentingan pribadi, untuk bersenang-senang.

c. Olahraga Prestasi (Olahraga Kompetitif): Merupakan jenis olahraga yang menekankan pada pencapaian prestasi atau kemenangan.

d. Olahraga Kesehatan (Olahraga Rehabilitas): Jenis olahraga ini sengaja dilakukan dengan tujuan untuk mempertahankan atau memperbaiki kondisi tubuh seseorang.

\section{Tahapan Program Sarana Kebugaran}

Terdapat 5 tahap dasar program umum sarana kebugaran untuk hasil yang diharapan, yaitu:

a. Pemanasan (Warm-up)

b. Pembakaran kalori (Aerobic)

c. Kelenturan

d. Pembentukan serta penguatan tubuh secara total

e. Pendinginan

\section{Jenis Latihan pada Sarana Kebugaran}

a. Latihan beban: Latihan menggunakan beban sebagai alat bantu untuk meningkatkan kontraksi otot. Beban yang digunakan bisa beban tubuh sendiri, beban bebas (barbel atau dumbbell), dan beban alat (alat mekanik/ elektronik).

b. Latihan kardio: Latihan untuk meningkatkan detak jantung tanpa penggunaan beban

\section{Ruang pada Sarana Kebugaran}

Ruang-ruang yang ada di sarana kebugaran :

a. Fitness space (ruang latihan kebugaran). mencakup peralatan kardiovaskular, angkat beban, area peregangan/ pemanasan/ pendinginan, lintasan lari indoor.

b. Ruang kelas latihan. Untuk kegiatan kebugaran tertentu, seperti yoga dan aerobik.

c. Ruang loker dan ruang ganti. Dibedakan berdasarkan jenis kelamin untuk berganti pakaian, menyimpan pakaian, mandi, dan toilet.

d. Ruang administrasi. Seperti kantor staff, resepsionis, penyimpanan, tempat untuk memperbaiki alat fitness.

e. Ruang pendukung untuk meningkatkan pengalaman pengunjung, interaksi sosial dan sebagai sumber pendapatan, seperti layanan makanan, retail pakaian dan peralatan atletik, penitipan anak, ruang pijat/ terapi fisik, tanning area.

f. Kolam renang indoor maupun outdoor. Termasuk kolam lap, kolam keluarga, kolam menyelam, dan kolam air panas.

g. Ruang luar seperti lapangan olahraga, lintasan lari outdoor, dan lintasan sepeda.

\section{Aktivitas Fisik Outdoor}

Semua jenis aktivitas olahraga di luar ruangan dapat menghilangkan suasana hati negatif, seperti ketegangan, kemarahan dan depresi. Berolahraga di ruang hijau dan alam terbuka dapat menjadi obat alami untuk mengatasi tantangan kesehatan yang dihadapi lingkungan perkotaan yang padat. Berikut merupakan manfaat olahraga outdoor:

a. Latihan di luar ruangan memberikan peluang untuk aktif secara fisik dalam lingkungan yang terus berubah. Beban angin membantu membakar lebih banyak kalori.

b. Lebih hemat karena tidak perlu bayar seperti gym.

c. Udara lebih bersih dan mendapat vitamin D dari paparan sinar matahari langsung. 


\section{Pengertian Relaksasi}

Teknik relaksasi merupakan suatu cara untuk mengatasi stress dan meningkatkan kesehatan jangka panjang dengan mengendurkan tubuh dan menenangkan pikiran.

\section{Jenis Relaksasi}

Secara garis besar, relaksasi terbagi menjadi 3 fokus utama, yaitu relaksasi otot, relaksasi melalui indera, dan meditasi. Lichstein (1988) membagi jenis teknik relaksasi sebagai berikut :

a. Autogenic Training: Prosedur relaksasi dengan membayangkan/ citra visual dan kesadaran tubuh agar seseorang berada pada kondisi relaksasi yang mendalam. Dengan membayangkan tempat yang damai, tenang, dan indah. Kemudian fokus pada sensasi fisik bagian-bagian tubuh, mulai dari aki hingga kepala. Misalnya fokus pada sensasi hangat, pernafasan yang lega, detak jantung yang pelan.

b. Progressive Training: Prosedur relaksasi dengan mengendurkan otot-otot yang tegang agar lebih relaks, lemas, dan tidak kaku. Tujuannya agar proses neurologis berjalan lebih baik dan tegangan emosi menurun.

c. Meditation: Prosedur kalik relaksasi dengan melatih konsentrasi atau memusatkan pikiran pada kata/ frase tertentu sebagai fokus perhatiannya. Biasanya dilakukan dengan duduk sambil menutup mata, dan posisi pasif, serta pernafasan teratur dan dalam. Tujuannya untuk menciptakan ketenangan diri.

\section{Pengertian Spa}

Spa adalah terapi atau penyembuhan melalui air. Air dianggap bermanfaat untuk melepaskan kelelahan dan menyegarkan tubuh serta pikiran.

\section{Jenis Spa}

Pada dasarnya spa dibagi menjadi 3 jenis, yaitu:

a. Mandi Uap/ Sauna: Ruang sauna didesain khusus menjadi ruang pemanas dengan temperatur tinggi dan kelembaban yang terjaga dengan baik. Biasanya ruang terbuat dari kayu tahan panas. Tujuan mandi uap ini untuk membantu merelaksasikan otot setelah lelah bekerja. Uap panas yang dikeluarkan akan membuka pori-pori kulit sehingga racun dan kotoran dalam tubuh dapat dikeluarkan. Sehingga kulit terasa kencang dan lebih bersih.Terdapat 2 tipe sauna, yaitu

- Dry sauna : tidak menggunakan air, biasanya menggunakan batu basal.

- Wet sauna : menggunakan air atau medium cair untuk memanaskan ruangan.

b. Berendam / Hydrotherapy: Teknik perawatan tubuh dengan menggunakan air (air hangat, panas, dingin, uap air, air es) dan bahan ramuan alami. Setelah mandi uap / sauna, dilanjutkan dengan berendam di dalam whirlpool dengan berbagai macam aroma rempah atau di bathtub pribadi dengan aromaterapi. Tujuannya untuk mempermudah peredaran oksigen dalam tubuh sehingga pernafasan menjadi lebih cepat. Kandungan mineral dalam air rendaman pun dapat merangsang pembentukan sel baru.

c. Pijat / Massage: Merupakan pemijatan pada jaringan lunak dengan menggunakan gerakan anggota tubuh atau alat bantu lainnya. Tujuannya untuk menstimulasi, membuat relaks, dan melancarkan peredaran darah.

\section{METODE}

Diawali dari metode pengumpulan data dengan observasi, wawancara dan studi dokumen/ literatur. Observasi dan wawancara berupa pengamatan langsung tapak dan wawancara dengan pengunjung dan pekerja di lingkungan sekitar Jalan Danau Sunter Selatan. Sementara studi dokumen/ literatur untuk mempelajari kajian teori berkaitan tentang Third Place, kesehatan, kebugaran, stress, wellness, dan preseden bangunan sejenis. Diambil dari media cetak maupun online. 
Terakhir metode yang digunakan dalam perancangan proyek ini adalah metode komparasi, metode ini mengacu kepada teori Place dalam Arsitektur menurut Christian Norberg Schulz dengan melakukan komparasi antara studi preseden dan kondisi eksisting tapak. Perancangan proyek ini dimulai dengan mengumpulkan studi preseden. Studi preseden di pilih dengan tolak ukur data proyek, konsep, program ruang, denah dan zonasi, gubahan massa, pola sirkulasi, tampak dan potongan, fasad bangunan, warna dan material, pengalaman ruang, dan interior. Setelah data tersebut terkumpul maka akan dilakukan studi lebih lanjut dan dilakukan komparasi dengan kondisi eksisting tapak mengikuti teori Place dalam Arsitektur.

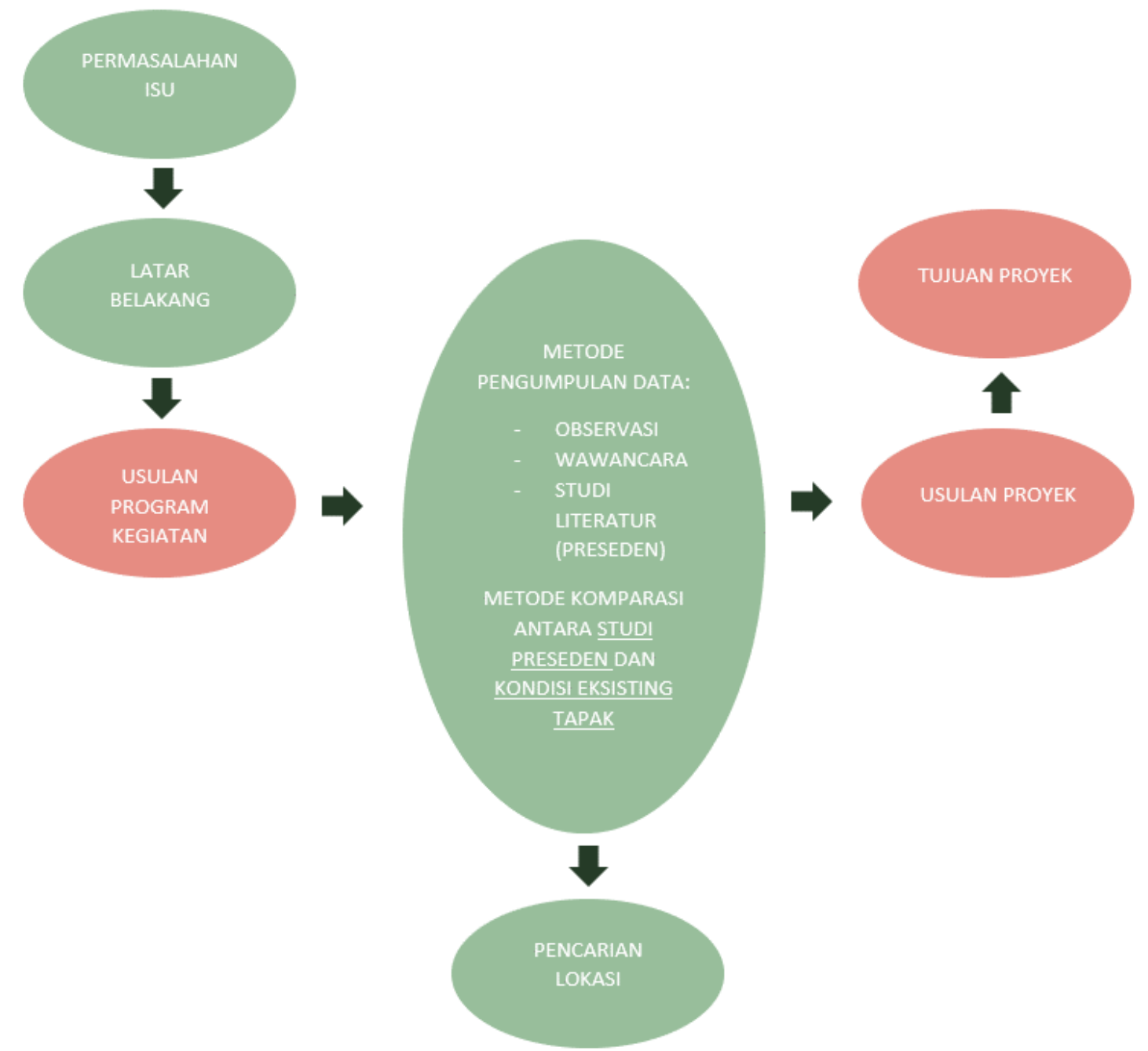

Gambar 1. Diagram Kerangka Berpikir Sumber : Penulis, 2019

\section{DISKUSI DAN HASIL}

Data Tapak

Tapak terpilih berada di Jalan Danau Sunter Selatan, Kelurahan Sunter Jaya, Kecamatan Tanjung Priok, Jakarta Utara.

Peruntukan : Perkantoran, Perdagangan, dan Jasa KDB Rendah

Luas Tapak : $7.263 \mathrm{~m}^{2}$

KDB $: 30 \%$

KLB $\quad: 1,2$

$\mathrm{KB} \quad: 4$

KTB $\quad: 40 \%$

Tipe : : Tunggal

$\mathrm{KDH} \quad: 45 \%$ 


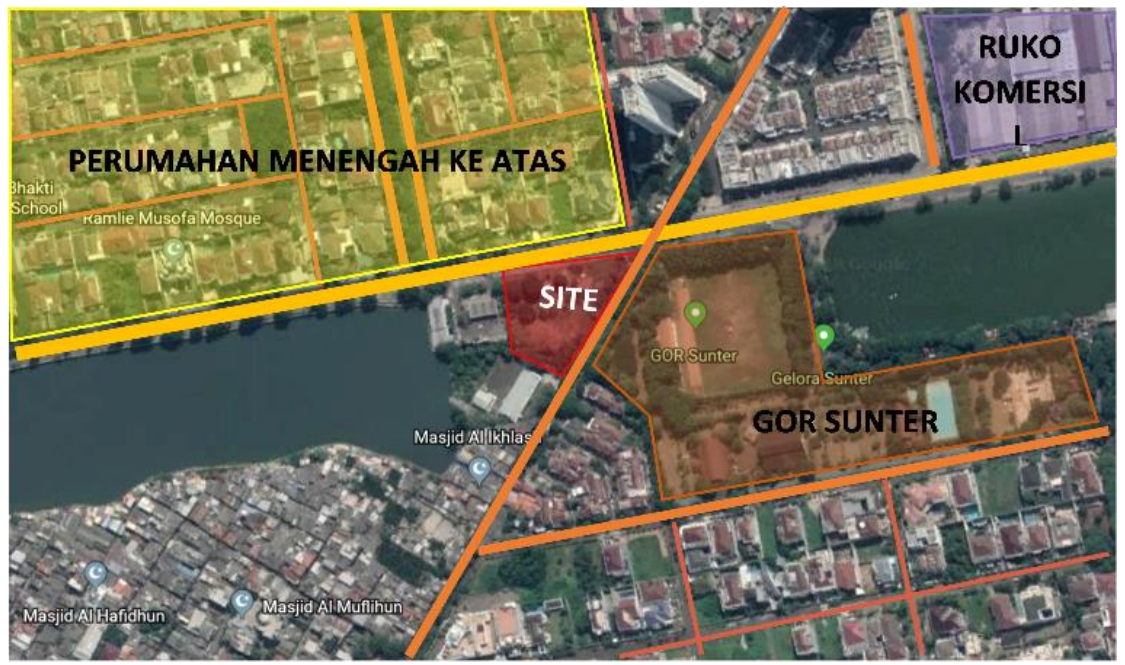

Gambar 2. Lokasi Tapak Terpilih

Sumber : Google Maps

Makro

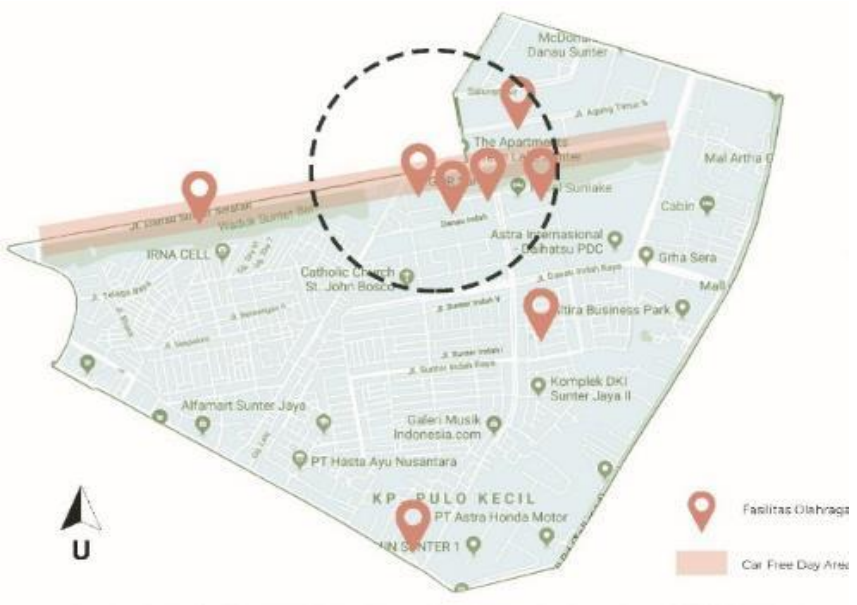

Gambar 3. Peta Kelurahan Sunter Jaya Sumber : Google Maps

Berdasarkan data dari Badan Pusat Statistik, jumlah penduduk di kelurahan Sunter Jaya adalah 72.900 jiwa dengan penduduk terbanyak berusia 35 - 39 (usia produktif) dengan persentase $10,68 \%$. Kelurahan Sunter Jaya memiliki fasilitas olahraga terbanyak dengan total 8 fasilitas olahraga. Hal ini membuktikan bahwa kelurahan Sunter Jaya memiliki apresiasi yang tinggi terhadap gerakan sehat dan fasilitas kebugaran.

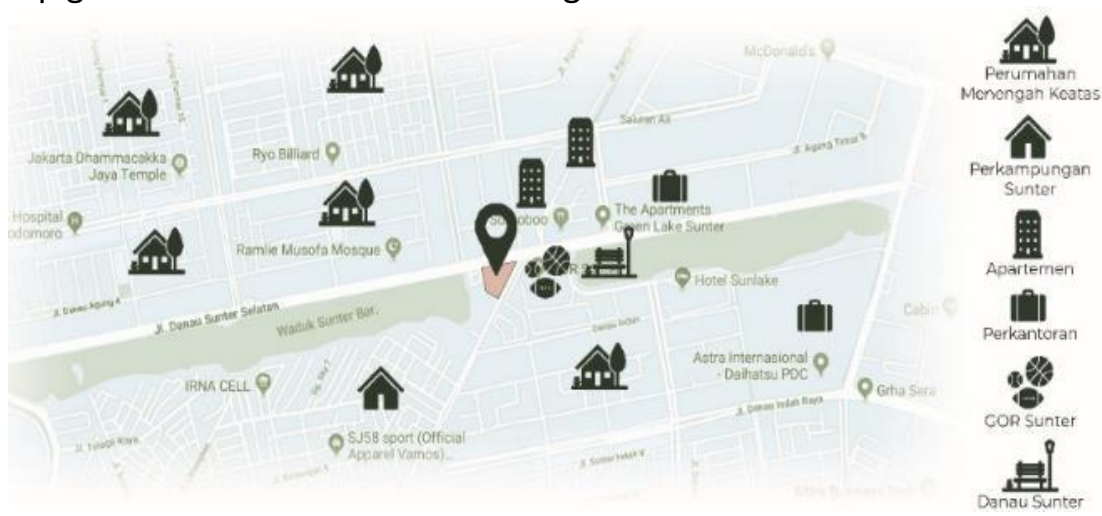

Gambar 4. Peta Fasilitas Sekitar Kelurahan Sunter Jaya Sumber : Google Maps 
Jalan Danau Sunter Selatan merupakan titik pusat aktivitas olahraga di kelurahan Sunter Jaya dengan adanya GOR Sunter serta lokasi Car Free Day di sepanjang Jalan Sunter Selatan, selain itu kawasan Jalan Sunter Selatan juga memiliki sarana rekreasi berupa Danau Sunter.

Mikro
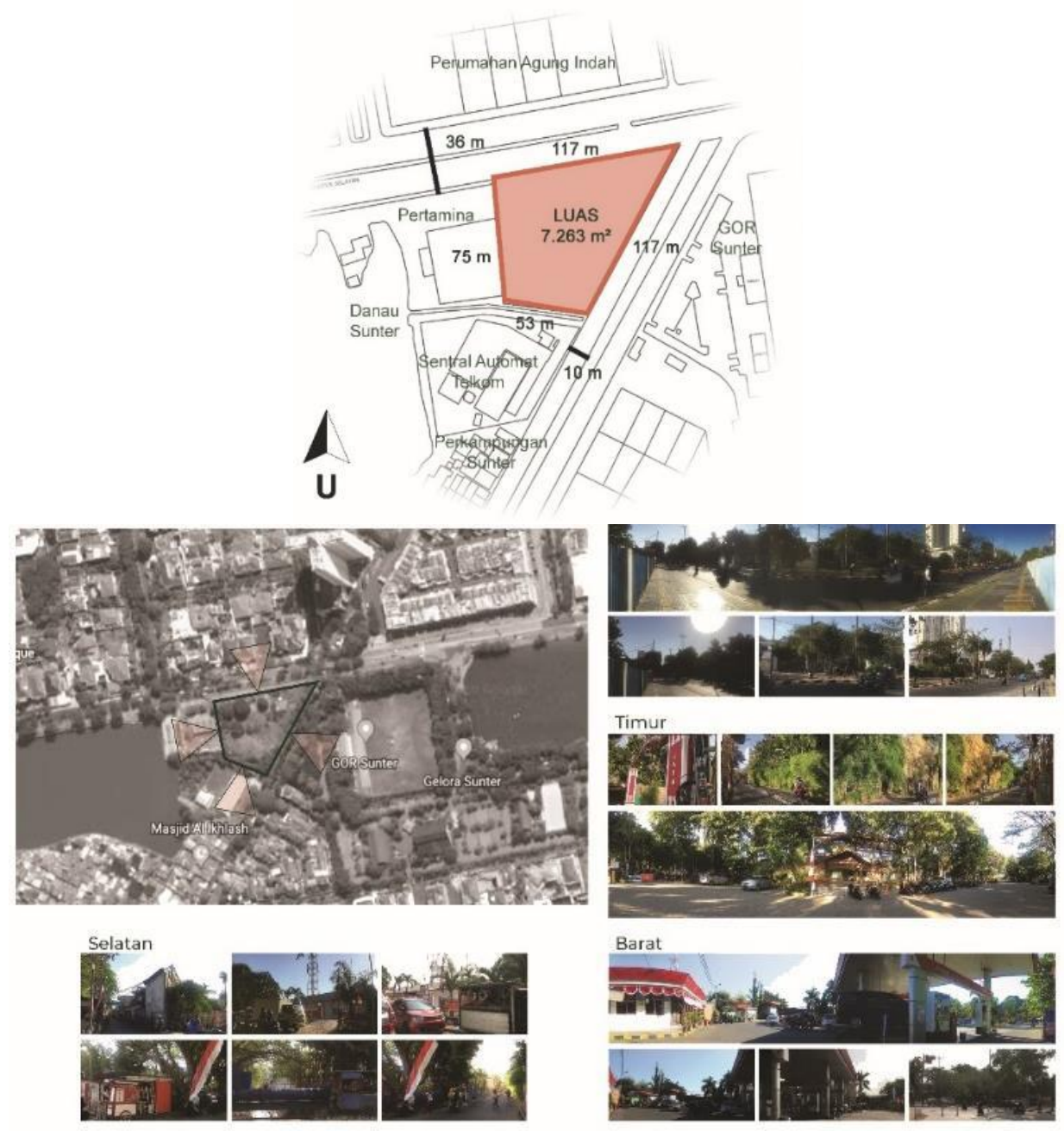

Gambar 5. Luas Tapak \& View ke Luar Tapak Sumber : Penulis, 2019

Pada sisi Utara tapak, berbatasan dengan jalan utama, perumahan menengah ke atas, apartemen Greenlake Sunter, dan ruko komersil. Sebagai jalan utama, kendaran melalui sisi Utara untuk putar balik, menuju Pertamina dan perkampungan Sunter, jalur pedestrian digunakan sebagai akses menuju GOR Sunter, Danau Agung, dan Danau Sunter Barat, sehingga sisi ini berpotensi sebagai entrance utama.

Pada sisi Timur tapak, berbatasan dengan jalan menuju perkampungan Sunter (Perumahan menengah ke bawah) dan GOR Sunter. Terdapat pembatas berupa pepohonan yang memisahkan jalan perkampungan Sunter dengan GOR Sunter yang berdekatan dengan akses perumahan menengah ke atas, aktivitas pada sisi ini adalah menunggu ojek, lari pagi dan sore, senam. Pada sisi ini berpotensi untuk side entrance bagi pejalan kaki dan pengguna sepeda.

Pada sisi Selatan tapak, berbatasan dengan saluran air Danau Sunter, Indihome dan perkampungan Sunter (Perumahan menengah ke bawah). Pada pagi hari dan Sore hari terdapat PKL yang berjualan di sepanjang jalan ini dan penduduk dari perkampungan Sunter olahraga (lari dan senam). View menuju sisi ini kurang baik sehingga dibutuhkan pengalih. 
Pada sisi Barat tapak, berbatasan dengan Pom Bensin Pertamina, tempat cuci mobil, tempat makan dan Danau Sunter Barat. Berdasakan wawancara dengan Bapak Kusuma pengawas Pertamina, pengunjung paling ramai datang pada jam 7 - 9 pagi dan jam 4 - 6 sore. rata-rata pengunjung berusia produktif dan pekerja kantoran. Polusi serta view pada sisi ini tidak baik sehingga sisi ini dapat dimanfaatkan sebagai area servis.

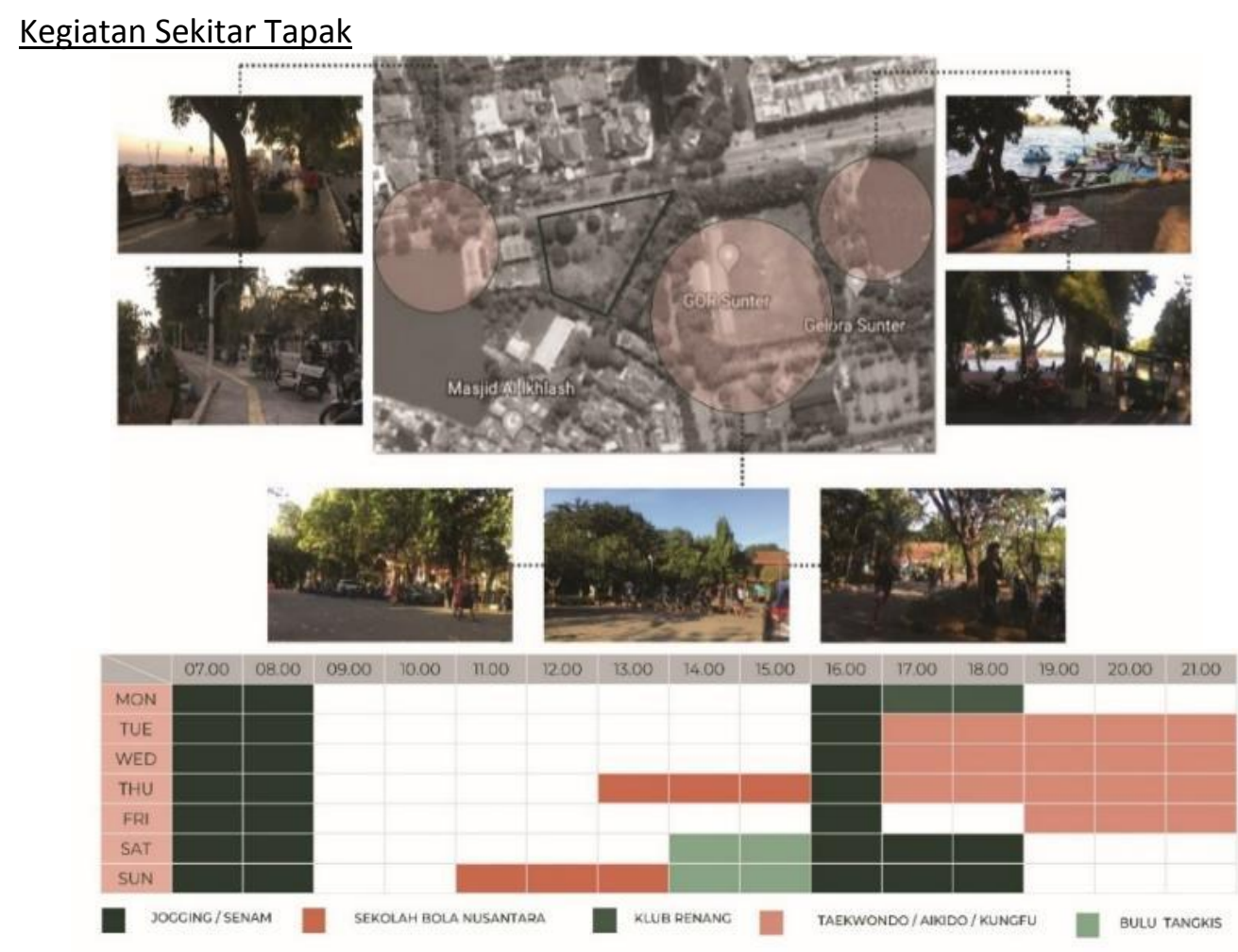

PKL DANAU SUNTER

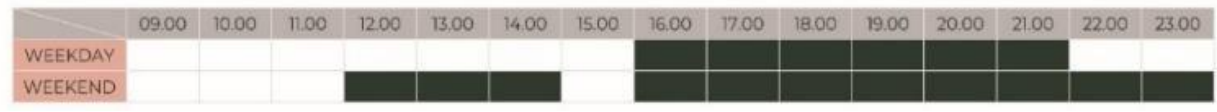

Gambar 6. Kegiatan Sekitar Tapak

Sumber : Penulis, 2019

Berdasarkan data, penduduk kelurahan Sunter Jaya melakukan berbagai aktivitas di sekitar Jl. Danau Sunter Selatan seperti jogging, senam, latihan bola, berenang, bermain bulu tangkis, taekwondo, aikido, Kungfu, makan, duduk, berbincang, memancing, bermain bebek danau sunter, dan bersepeda untuk rekreasi, menjaga kebugaran tubuh dan mengisi waktu luang. Permasalahan yang terjadi adalah terdapat mix activity yang tidak terkontrol di beberapa titik sekitar JI. Danau Sunter Selatan pada pukul $16.00-18.00$ yaitu GOR Sunter, Danau Sunter Timur dan Danau Sunter Barat sehingga dibutuhkan sarana rekreasi, dan sarana kebugaran yang nyaman dan aman bagi penduduk kelurahan Sunter Jaya.

\section{Program Organisasi Ruang}

Program utama merupakan hasil dari studi, kajian dan survey terkait metode penangan stress dan karakteristik Third Place serta kebutuhan penduduk sekitar kelurahan Sunter Jaya, sementara program pendukung merupakan hasil studi preseden. Persentase serta luasan yang tertera pada diagram program usulan juga merupakan hasil studi ruang yang terdapat pada literatur program bangunan serupa. Program yang terbentuk berdasarkan kebutuhan penduduk sekitar kelurahan Sunter Jaya berupa sarana rekreasi, dan sarana kebugaran yang nyaman dan aman bagi penduduk. Program ini diharapkan dapat menjadi Third Place bagi penduduk kelurahan Sunter Jaya. 
Pengelompokan ruang-ruang dibagi menjadi:

- Area Latihan Fisik: Wadah pelatihan kekuatan tubuh dalam ruangan. Terdapat area latihan untuk olahraga dengan peralatan fitness seperti kardiovaskular dan angkat beban. Serta studio olahraga untuk kelas fitness dan relaksasi berkelompok; dance, aerobik, muay thai, pilates.

- Area Relaksasi: Wadah untuk relaksasi otot yang terlalu tegang dan menyedarkan jasmani, seperti adanya spa, sauna, terapi. Terapi yang ditawarkan berupa terapi dengan air (hydrotherapy).

- Area Outdoor: Wadah olahraga fisik di ruang luar, seperti taman untuk yoga dan meditasi, jalur untuk bersepeda dan jogging. Bertujuan agar kegiatan kebugaran dan relaksasi dengan suasana lingkungan alam dapat menciptakan suasana tenang dan relaks bagi tubuh.

- Area Penunjang: Merupakan area makan setelah aktivitas olahraga yang menguras tenaga. Area ini menyediakan makanan dan minuman sehat dan organik, baik bahan mentah maupun siap saji. Pengunjung akan mendapat pengalaman unik karena dapat memilih sendiri bahan makanan, cara memasak (dimasakin/ masak sendiri, digoreng/dibakar/ditim, tambahan saos), cara makan (duduk lesehan, duduk di kursimeja, duduk sandaran), dan menaruh sendiri peralatan makan yang sudah digunakan di tempat yang sudah disediakan.

\section{Persentase \& Luas Program}
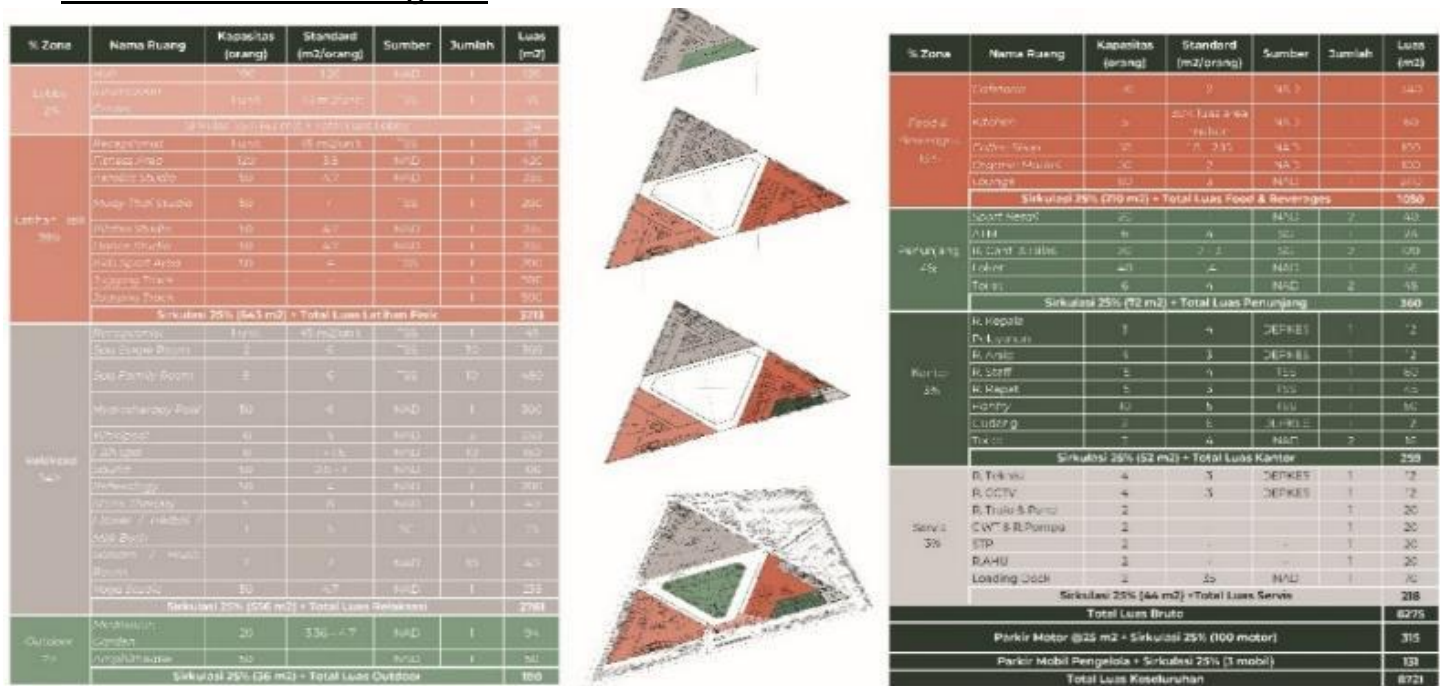

Gambar 7. Diagramatik Program

Sumber : Penulis, 2019
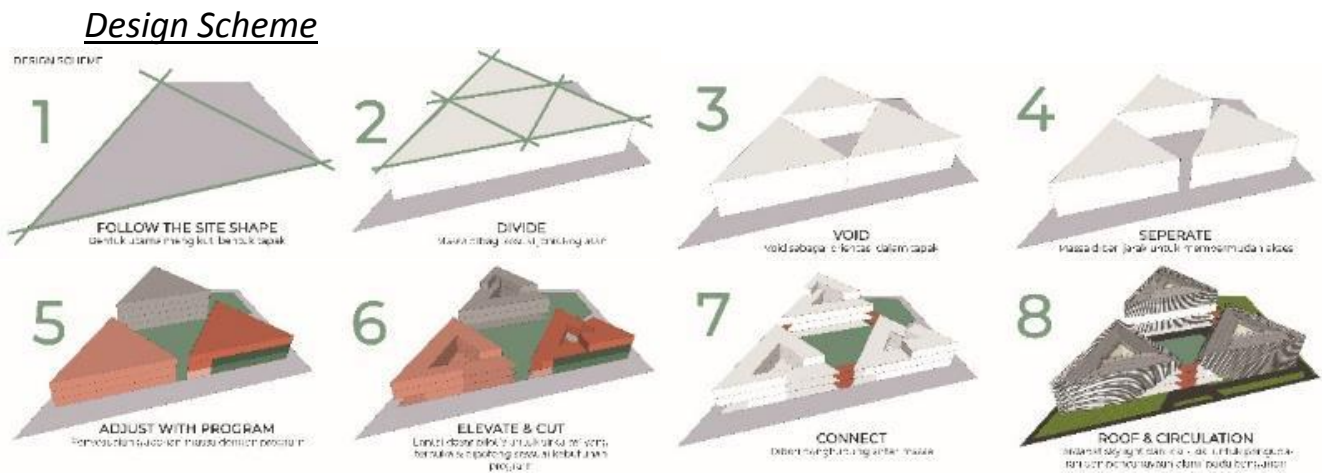

Gambar 8. Design Scheme

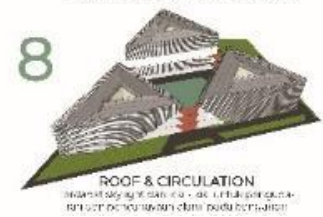

Sumber : Penulis, 2019 


\section{Site Plan Denah}

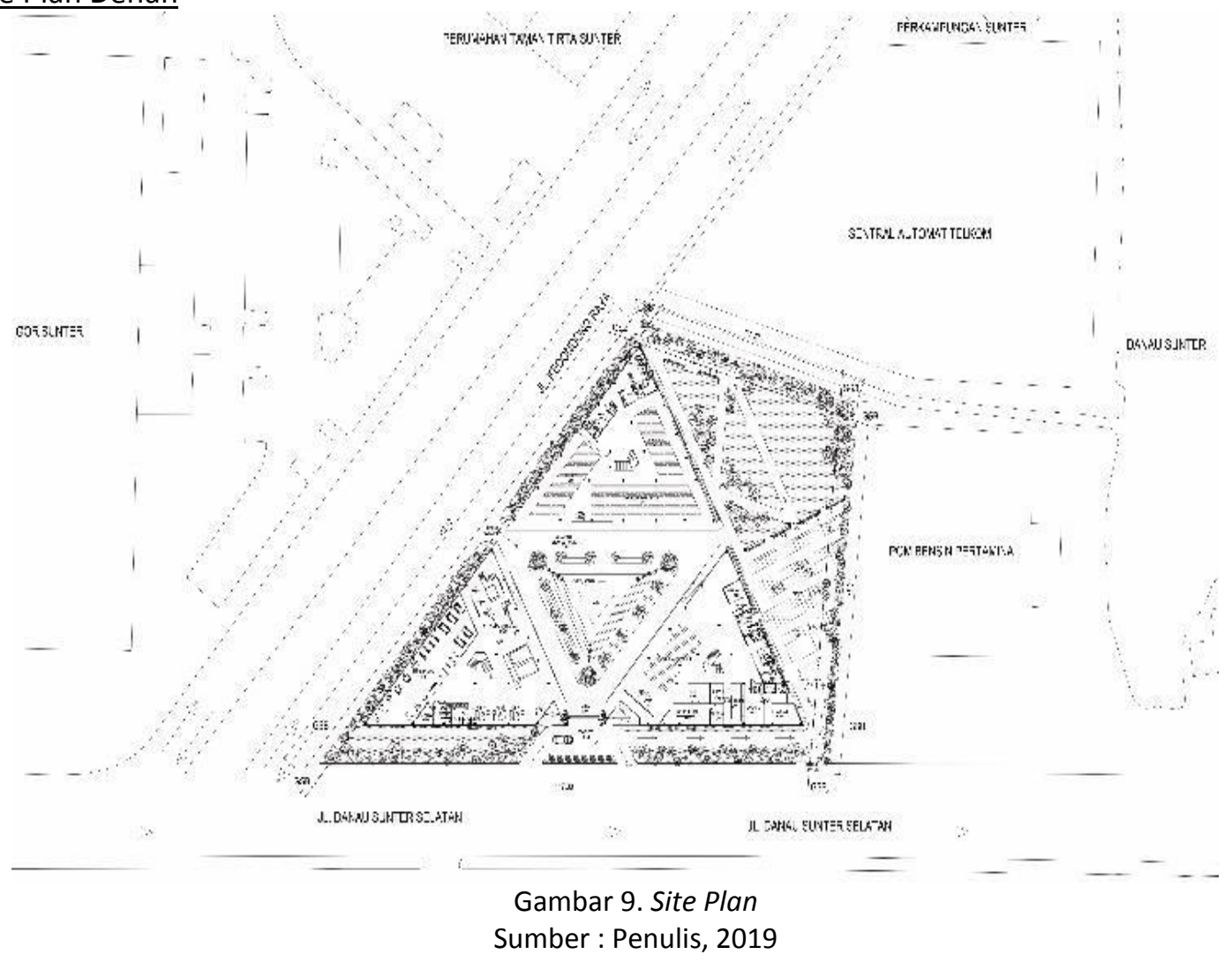

Entrance utama menuju proyek ini melalui Jalan Danau Sunter Selatan sedangkan untuk pejalan kaki, entrance melalui Jalan Kedondong Raya yang juga merupakan akses menuju perkampungan Sunter. Terdapat amphitheater yang menjadi center point pada proyek ini.

\section{Potongan}

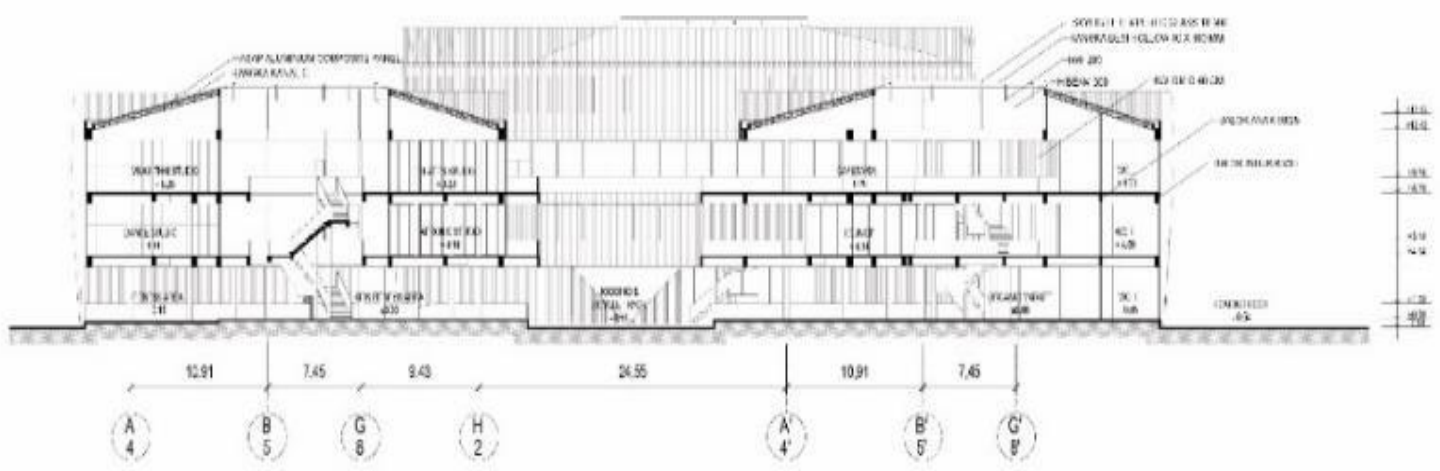

Gambar 10. Potongan

Sumber : Penulis, 2019

Struktur pada bangunan menggunakan kolom beton bertulang o $40 \mathrm{~cm}$ serta balok induk $60 / 30 \mathrm{~cm}$ dan balok anak $50 / 25 \mathrm{~cm}$. Dinding menggunakan batu $1 / 2$ bata $15 \mathrm{~cm}$ dengan finishing semen ekspos serta dinding curtain wall. Pada bagian atap terdapat skylight dengan material tempered glass $10 \mathrm{~mm}$ dengan rangka besi hollow $20 \times 100 \mathrm{~mm}$ untuk memaksimalkan pencahayaan dan pengudaraan alami. 


\section{Tampak}

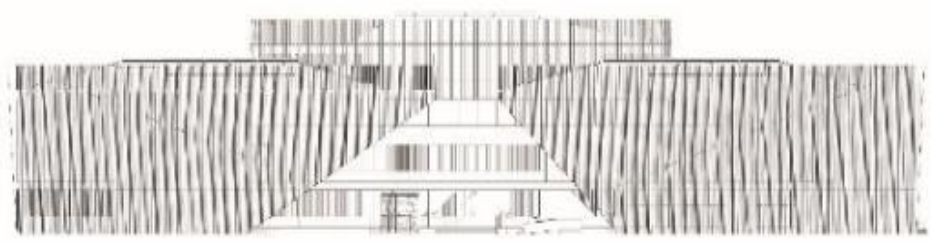

TAMPAK DEPAN

SGLA 1.300

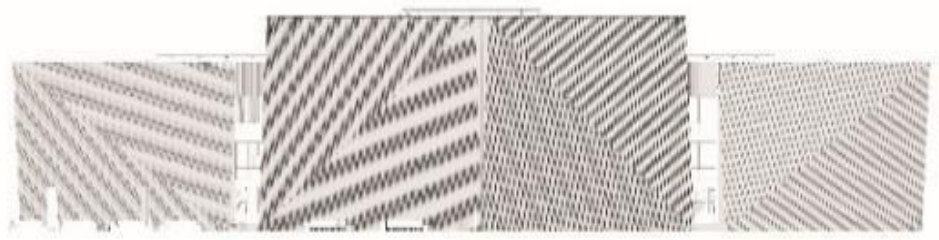

TAMPAK BELAKANG

SRALA 1300

Gambar 11. Potongan

Sumber : Penulis, 2019

Tampak dari bangunan ini terlihat dinamis dengan bentuk second skin yang menggunakan geometri segitiga untuk mencerminkan bentuk dasar bangunan. Lantai satu dibuat pilotis sehingga memberi kesan mengundang dan terbuka serta mempermudah sirkulasi pengunjung dari satu area menuju area lainnya. Pada kedua sisi entrance, pengunjung akan melihat center point dari proyek ini yaitu amphitheater. Material yang digunakan untuk second skin berupa panel aluminium. Warna pada proyek ini didominasi dengan warna abu-abu dan silver sehingga memberi netral.

\section{KESIMPULAN DAN SARAN}

\section{Kesimpulan}

Untuk mengatasi stress akibat kesibukan sehari-hari dan menjaga kesehatan masyarakat di Jakarta, salah satunya pada kelurahan Sunter Agung maka diperlukan sarana yang dapat mewadahi kebutuhan rekreasi dan kebugaran masyarakat berupa Third Place. Program utama yang ditawarkan pada proyek ini terdapat area fitness, studio olahraga, spa, sauna, hydrotherapy pool, jogging track, bicycle track, yoga \& meditation park, dan area penunjang seperti sport retail dan tempat makan. Konsep yang membedakan proyek ini dengan fasilitas sejenis yang sudah ada yaitu penerapan program olahraga maupun relaksasi yang kembali kepada alam, tidak sekedar di dalam ruangan terus menerus, dan tidak bergantung pada peralatan fitness saja. Alam yang ada (area hijau maupun area biru) dapat diolah dari segi arsitektur untuk dimanfaatkan sebagai sarana berolahraga dan berelaksasi. Pemanfaatan unsur lingkungan ini pun secara alami memberikan ketenangan, kedamaian, Saran dan relaksasi bagi pengunjungnya.

Saran penulis sebaiknya proyek fasilitas rekreasi dan kebugaran seperti ini semakin dikembangkan, sehingga masyarakat dapat mengisi waktu luang dan melepas kepenatan dengan berolahraga, masyarakat dapat tetap sehat dan bugar, sekaligus mendapatkan pengalaman dan komunitas baru untuk bersosialisasi. 


\section{REFERENSI}

Badan Pusat Statistik, Kecamatan Tanjung riok Dalam Angka 2018

Badan Pusat Statistik, Kota Jakarta Utara Dalam Angka 2019

Barton J, Hine R, dan Pretty J. (2009) "The Health Benefits of Walking in Greenspaces of High Natural and Heritage Value", J Integr Environ Sci, 2009, 6(4), hlm. 261-278.

Coon, J. T. dkk. (2011) Does Participating in Physical Activity in Outdoor Natural Environments Have a Greater Effect on Physical and Mental Well-being than Physical Activity Indoors? A Systematic Review. (Environ Sci Technol, 2011), hlm. 1761-1772.

Eric. G. Mion, "Fitness Centers", wbdg.org/building-types/community-services/fitness-centers

Gladwell, V. F, dkk., (2003) "The Great Outdoors: How a Green Exercise Environment Can Benefit All." Extreme Physiology \& Medicine 2

Gold, S. M. (1980). "Urban Recreation Planning". California: Mc GrawHill Book Company

International Labour Organization. (2017). "Laporan Ketenagakerjaan Indonesia 2017", https://www.ilo.org/jakarta/whatwedo/publications/WCMS_613628/lang--en/index.html

Jeanne Segal, "Stress Symptoms, Signs, and Causes", helpguide.org/articles/stress/stresssymptoms-signs- and-causes.html.

Lutan, R. (2000). Asas-asas Pendidikan Jasmani Pendekatan Pendidikan Gerak di Sekolah Dasar. Jakarta: Direktorat Jenderal Olahraga, Depdiknas.

Maxmanroe. (2019). "Pengertian Stress Adalah, Jenis dan Faktor Penyebab Stress", maxmanroe.com/vid/umum/pengertian-stress.html

McLean, D. D, dkk. (2018). "Kraus' Recreation and Leisure in Modern Society Elevent Edition". United States: Jones \& Bartlett Learning

Oldenburg, R. (1997). "The Great Good Place". Cambridge: De Capo Press Book

Pasaribu, M. "Sejarah Fitness", mangihot.com/2017/02/sejarah-fitness.html.

Steemers, K. (2018) "Architecture for Well-being and Health", Daylight and Architecture, 23, Juli 2018. 